\title{
Alinhamentos de governação e a situação de sem-abrigo em Portugal: perigos e insuficiências da orientação para/pelo mercado
}

\author{
Governance alignments and homelessness in Portugal: Perils and inadequacies of \\ guidance for/by the market
}

\section{Sónia Mairos Ferreira*}

\begin{abstract}
Resumo:
No presente artigo analisam-se, criticamente, as implicações da implementação de um estilo governativo orientado pelo e para o mercado, e de matriz reflexiva, no que diz respeito à problemática da situação de sem-abrigo. Para este efeito, exploram-se, num primeiro momento, as componentes chave deste alinhamento na UE, apontando-se as suas intencionalidades e efeitos (in)diretos, particularmente no que concerne as políticas e práticas de conceitualização e intervenção neste domínio. 0 ponto seguinte é devotado à reflexão crítica sobre as especificidades do caso Português, elencando-se as prioridades manifestas e apontando, com base em referentes ilustrativos múltiplos, as incongruências e insuficiências de maior relevo.
\end{abstract}

Palavras-chave: Situação de sem-abrigo. Políticas sociais. Governação orientada pelo/para o mercado. Privação

\begin{abstract}
:
In this article, the implications of the implementation of a governance style guided by and for the market, and of reflexive matrix, concerning the problematic of homelessness, are analyzed. To accomplish this purpose the author explores, at first, the key components of this alignment within the EU, pointing out its intentions and (in) direct effects, particularly concerning the conceptualization and intervention policies and practices of conceptualization and intervention in this domain. The next point is devoted to the critical reflection on the specifics of the Portuguese case, listing the manifested priorities and pointing, based on multiple illustrative referents, the inconsistencies and inadequacies of greater relevance.
\end{abstract}

Keywords: Homelessness. Public socials. Governance orientated by/for the market. Deprivation.

\section{Introdução}

Ilustração de vulnerabilidades severas nos mecanismos de regulação favorecidos na generalidade dos países desenvolvidos, com evidentes repercussões na União Europeia, a

\footnotetext{
* Doutora em Formação de Adultos e Educação Permanente e Professora Auxiliar na Faculdade de Psicologia e de Ciências da Educação da Universidade de Coimbra, Portugal. Professora nos domínios das Ciências da Educação, Formação de Adultos e Educação Permanente, Exclusão e pobreza. E-mail: smairosferreira@fpce.uc.pt
} 
situação de sem-abrigo retrata, com particular agudeza, os efeitos dramáticos da intensificação de arduidades experienciadas por um número crescente de pessoas e famílias, perante às crescentes exigências inerentes à vida em sociedade. Assumida como a face mais severa da pobreza extrema, dado corporizar, sob um conjunto diversificado de configurações vivenciais [e.g., estadia em casa de conhecidos/as, ocupação de casas abandonadas, pernoite em espaço público ou não adequado para utilização por humanos (e.g., fábricas abandonadas, estábulos, garagens)], constrangimentos severos no cumprimento dos direitos e liberdades fundamentais, o aumento da sua expressão denota os efeitos nefastos das opções governativas, de matriz orientada pelo/para o mercado, privilegiadas em muitas democracias ocidentais. Expectável, se tivermos em consideração as debilidades que os mecanismos de governação, implementados em diversos territórios, vinham a acusar (tendo estas sido agravadas em resultado da crise financeira e da sua subsequente expansão a outras esferas da vida em sociedade), a centralidade que este estudo tem vindo a assumir na contemporaneidade gera inquietações e inseguranças (FEANTSA, 2010b; FERREIRA, 2015a, 2015b; LEE; GREIF, 2008; PAASCHE, 2012; WORLD HEALTH ORGANIZATION, 2010).

Este artigo visa, precisamente, contribuir para a reflexão sobre estas matérias, em específico no que concerne aos efeitos da adoção de políticas orientadas pelo/para o mercado no âmbito da definição de políticas públicas destinadas ao combate da situação de sem-abrigo, com repercussões diretas nos âmbitos da conceitualização, estudo e intervenção.

\section{Diretrizes de governação, alinhamentos estratégicos e a situação de sem abrigo}

Qualificada como "exemplo mais extremo de pobreza e exclusão social nas sociedades contemporâneas" (BROUSSE, 2004, p. 4) ou como "problema complexo e multidimensional, resultante da combinação de processos de exclusão habitacional e social" (EUROPEAN COMMISSION, 2007, p. 30), só para nomear alguns exemplos, a constatação da sua severidade é frequente nas produções da UE e nos discursos dos seus representantes (FERREIRA, 2015a, 2015b, 2015c). Embora descrita como uma problemática que urge suprimir na Europa, socialmente coesa, que se pretende edificar, permanece como um dos fenômenos mais graves com que esta se confronta, perante a qual revela 
uma posição pouco articulada e com eficácia questionável (BUSCH-GEERTSEMA et al., 2010; EUROPEAN PARLIAMENT, 2011; FEANTSA, 2010b).

Exposta como prova irrefutável dos efeitos nefastos do "cocktail neoliberal tóxico de política econômica" (PALLEY, 2013, p. 1), o seu agravamento, em dimensão e diversidade, na última década, tem vindo a ser exposto sinal da imprescindibilidade de alteração das orientações governativas implementadas pela UE e pelos seus estados membros, no que diz respeito às políticas e práticas de promoção da democratização do acesso e usufruto de bens e liberdades, assim como da igualdade de direitos e oportunidades entre pessoas e povos. Porém, ao contrário do que os defensores desta alteração de azimute defendem, o macro modelo de governação privilegiado em território Europeu, de clara orientação pelo e para o mercado, tem ganhado robustez e é hoje apresentado, por governantes e organismos com responsabilidade governativa, como $a$ opção ajustada face aos desafios com que o velho continente se confronta na contemporaneidade (MILIOS, 2013; ZACUNE, 2013). Assumindo, em paralelo, as posições de causa da conjuntura econômica, financeira e social atual, e de (única) solução perante às sequelas que provoca, é apresentado, pelos seus defensores, como a opção estratégica de maior utilidade no combate aos desafios com que as democracias europeias se confrontam. Aponta-se, portanto, como referentechave, a crise de 2008, por um lado tida como responsável pela implementação de medidas de contenção financeira e de diminuição da regalias dos cidadãos, e, por outro, como o fantasma cujo ressurgimento se teme (FERREIRA, 2015a). Assim, e para evitar uma nova crise, um elevado número de pessoas e famílias é convocado a participar num esforço de robustecimento das economias dos países, prescindindo, para isso, de privilégios e regalias que detinham.

Nota-se, contudo, que as exigências decorrentes desta matriz de governo não se disseminaram de forma homogênea pelos diversos segmentos das populações. Sabemos que as suas sequelas são múltiplas e conjugam-se segundo formatos distintos em grupos populacionais diferenciados, sendo particularmente expressiva a sua ação naqueles que já experienciavam privação e vulnerabilidade no período pré-crise e, por outro lado, muito pouco relevante no segmento de maior riqueza (INSTITUTO NACIONAL DE ESTATÍSTICA, 2011; CALLAN et al., 2011). Indicadores atestam uma tendência incremental de subjugação a uma matriz econômica de tipo predador (COHEN; DELONG, 2010), devido, em grande 
medida, à repriorização do crescimento econômico em detrimento do bem-estar e qualidade da vida das populações (EUROPEAN CENTRAL BANK, 2011; FERREIRA, 2015a; INSTITUTO FINANCEIRO PARA O DESENVOLVIMENTO REGIONAL, 2011). Num registo que se autoalimenta das suas insuficiências, esta primazia do "lucro sobre as pessoas" (CHOMSKY, 1999) sustenta-se, em síntese, no argumento de que para asseverar a preservação de um regime respeitador de direitos e liberdades é imprescindível adotar um regime de progressiva limitação desses mesmos direitos e liberdades, para a maioria dos membros da população. Aumentam-se, por esta via, as desigualdades e disparidades, extremando-se, para os mais pobres, as dificuldades em assegurar autonomia e bem-estar, associadas a maior precarização e vulnerabilidade (e.g., laboral, habitacional); enquanto, no polo extremo, aposta-se em regulamentações perpetuadoras da manutenção de bens e regalias adquiridas, em estreita associação com investimento na amplificação de margens de lucro.

Em concomitância com este crescente domínio dos mercados e das suas leis sobre as pessoas e os seus direitos, corporificou-se, no contexto da produção legislativa e normativa emanada na última década pela UE (e pelos seus estados membros), uma clara orientação, no contexto das Políticas Sociais, de matriz reflexiva (FUREDI, 2006a, 2006b). Defende-se, sem grandes reservas, a ideologia de que é o indivíduo o responsável (em todo ou nas dimensões estruturantes de vivência em sociedade) pelas características (bem como pelo grau de ajuste) que assume a sua (não) inserção em sociedade (FERREIRA, 2015a, 2015d; FUREDI, 2006a, 2006b; McNAUGHTON, 2008, 2010). Para este efeito, assume-se, de forma consciente e programada, uma generalizada desconsideração pelas eventuais insuficiências severas do paradigma dominante, seja no que concerne aos seus princípios ou as medidas privilegiadas no contexto da sua implementação (e.g., contributo das políticas sociais para a manutenção de pobreza; discriminação no acesso/usufruto de modalidades de apoio social).

No âmbito desta matriz, não constitui surpresa que vejamos caracterizada a situação de sem-abrigo como "a escolha direta de uma indivíduo racional ou o resultado de outras escolhas de um indivíduo desviante" (PARSELL; PARSELL, 2012, p. 425), sendo esta consideração suportada por duas referências complementares. A primeira destas resulta da assunção, apresentada sem qualquer sustentação efetiva, de que nas democracias 
ocidentais, estão criadas as condições para o exercício, em circunstâncias de paridade, da liberdade e da autonomia, cabendo, por conseguinte, a cada um/a a responsabilidade de tomar decisões e, também, de assumir as consequências delas decorrentes. Em resultado, a ausência de habitação, associada a um quadro de pobreza extrema, só pode resultar de dois fatores essenciais: ou a situação de sem-abrigo se deve a uma escolha desejada e assumida pelo/a próprio/a, ou, sempre que o discurso da pessoa contraria esta alusão, é a severidade das fragilidades e limitações individuais que the impedem a vivência adaptada em sociedade (FUREDI, 2006a, 2006b; McNAUGHTON, 2008, 2010; PARSELL; PARSELL, 2012) Nota-se que qualquer uma dessas pretensas explicações radica, na sua base, na desvalorização de dimensões e fatores, não imputáveis à pessoa, e que sustentariam as dificuldades experienciadas (e.g., ausência de oferta habitacional a baixo custo). Desta opção de (in)visibilização de determinados fatores e dimensões em detrimentos de outros resulta, a nível da definição e priorização de políticas públicas sobre esta matéria, um acentuado enviesamento no sentido da aposta na colmatação de supostas fragilidades/lacunas manifestas pela pessoa, em oposição ao combate de fatores estruturais e econômicos (FEANTSA, 2010a, 2010b; FERREIRA, 2015a, 2015d; SPINNEWIJN, 2009). Assim se explica que, em face de um cenário econômico e social cada vez mais exigente, os governos centrem as suas preocupações, não na regulação das desigualdades e na reequilibração de vulnerabilidades (e.g., diminuição da carga fiscal), mas sim na promoção de processos de empoderamento dos/as seus cidadãos/as, nessa conjuntura conceitualizados/as como realidades individuais (não membros atuantes de coletividades), no sentido de que por meio dele sejam capazes de fazer as escolhas certas e de se comportar em consonância, na senda da sua transformação neste agente autônomo responsável ideal.

Sublinhe-se que este ethos não informa apenas as agendas e as opções políticas, sendo coextensivo às estratégias e ações implementadas por organismos e profissionais. Mais do que participantes informados, as pessoas são integradas em programas e medidas que visam o seu tratamento, suporte e aconselhamento. A operacionalização da políticas sociais assume, assim, uma abordagem predominantemente individualista que visa a desagregação da pessoa do(s) seu(s) grupo(s) de referência e a sua gestão enquanto cliente ou paciente de um serviço, criado com o propósito de o preparar para a reinserção, isto é, 
colmatar as suas lacunas e défices. Estas políticas do comportamento contribuem para a atomização do indivíduo, e para a precarização dos laços sociais e comunitários. Como adverte Furedi (2006a, p. 29),

[...] a transformação do cidadão num paciente tem o potencial de alterar a relação entre as pessoas e as instituições públicas. Ao novo contrato social terapêutico encontra-se subjacente a assunção paternalista de que os sujeitos vulneráveis necessitam de gestão e de 'suporte' oficial e do estado. De facto, em tudo menos no seu nome deixa de ser um contrato social, de todo, e transforma a relação entre o público e o estado numa transação individual.

Enraizada num imperativo de teor moralista, esta política de matriz reflexiva, enferma de limitações várias, das quais releva a não clarificação dos valores e premissas em que se fundamenta, aos quais se associa manifesta indefinição de intenções e de direção. Seria, precisamente, essa carência de explicitação de propósitos-chave, no que diz respeito às tarefas de governação, que provocaria este acentuado incremento de cuidado com a microgestão de comportamentos, opção que esconderia, em rigor, consciente fuga à lide com outras matérias de relevo (e.g., manutenção de desigualdades no acesso a bens e regalias). Fortalece(u)-se, por esta via, a formalização de um "regime do social", que se corporifica numa elevada diversidade de agências governamentais, e na afetação, no contexto da implementação de medidas de colmatação das lacunas dos cidadãos/as vulneráveis, de especialistas, trabalhadores/as sociais, voluntários/as, entre outros agentes, para o trabalho nesses domínios. As suas funções implicam a assunção, em paralelo, do papel de parceiros e tutores, na efetivação de processos de capacitação e de apoio na minimização e gestão de riscos dos seus pares que manifestam dificuldades/limitações, na senda da sua evolução ao estatuto de cidadão/a autônomo/a, responsável, ideal (McNAUGHTON, 2008). Para que tal transformação possa materializarse, espera-se que os/as excluídos/as se sujeitem, portanto, à ação de um conjunto de instrumentos de regulação que o próprio sistema disponibiliza cabendo ao próprio promotor das medidas a avaliação do seu sucesso e adequação.

\section{Especificidades do caso português}

Embora com singularidades face a outros cenários europeus, a abordagem implementada em Portugal no âmbito da formulação de políticas sociais e, em específico, 
de combate à situação de sem-abrigo não se distancia da linha de orientação exposta no ponto precedente. Sem intenção de exaustividade a nível da exposição das insuficiências das propostas de intervenção sobre esta problemática, devotamos os parágrafos seguintes à ilustração das sequelas mais notórias desta matriz reflexiva. Com este intuito, apresentamos exemplos ilustrativos desse reduzido investimento na compreensão da situação de sem-abrigo e, em articulação, de modesto esforço no sentido do seu combate.

Sublinha-se, como nota introdutória a este ponto do artigo, que o compromisso avocado pelo Governo Português, constante dos objetivos estabelecidos nos Planos Nacionais de Ação para a Inclusão e na Estratégia Nacional para a Integração de Pessoas Sem-abrigo, assenta na indicação (direta e não discutida) de que

$$
\begin{aligned}
& \text { existem alguns fenômenos que configuram formas extremas de pobreza e } \\
& \text { exclusão, como é o caso das pessoas que por qualquer razão correm o risco de } \\
& \text { perder, ou perderam o seu direito à habitação, estando, ainda, em muitos casos, } \\
& \text { comprometido o acesso a outros direitos (GIMAE, 2009, p. 5). }
\end{aligned}
$$

Não se problematizam, porém, fatores externos à pessoa que sustentam a emergência e manutenção destas perdas, nem se abordam as implicações delas decorrentes, nomeadamente em relação à eventual redefinição de políticas e estratégias de ação (FERREIRA, 2015a). Em consequência, se bem que apontada como uma violação dos direitos humanos, assim como dos direitos e liberdades constantes na Constituição da República Portuguesa, entre outros normativos em vigor, surge exibida como uma realidade, sobre a qual não se prevê solução eficaz. Em contraste, vemos neles longos parágrafos dedicados à justificação da sua existência a partir de: (i) análise de insuficiências na implementação de ações, (ii) desconhecimento do fenômeno por parte de entidades e profissionais, ou (iii) do desinteresse e desinvestimento manifestado pelos/as seus destinatários/as, na participação nas diversas iniciativas.

Vulgariza-se, por um lado, a ilusão de que as políticas sociais abraçadas, e os alinhamentos estratégicos privilegiados, são suficientes e adequados perante as dificuldades que as pessoas e famílias em situação de sem-abrigo experienciam, sendo necessário, somente, que estas se mobilizem para a mudança. A aceitação das medidas e propostas existentes, nas condições e circunstâncias definidas pelos/as especialistas (e que atendem às regras impostas pelo órgão financiador - neste cenário regulador da ação e de avaliador do seu ajuste), resultará na reinserção em sociedade. Pelo oposto, os insucessos 
nesse percurso de reinserção, tipicamente avaliados a partir do critério "autonomia financeira" [traduzida, de forma prioritária, em inserção laboral; mas admitindo, ainda, outras modalidades (e.g., obtenção de reforma, na atribuição de subsídio)], são apresentados como derivados da não motivação para a prossecução de objetivos de vida alternativos (à pobreza) e ao elevado número e gravidade das lacunas que as pessoas apresentam (FERREIRA, 2015a, 2015d). Enredadas num ciclo, autossustentado, de vulnerabilidades e de privação, as pessoas em situação de sem-abrigo permanecem, por longos períodos de tempo, reféns de programas e medidas, desenhados e implementados com o propósito de corrigir os seus problemas e lacunas (segundo diferentes agentes). Sem margem real de decisão sobre processos ou critérios de avaliação do seu "potencial de inserção", permanecem dependentes da apreciação positiva dos agentes e organismos com quem interagem, para a continuidade de obtenção de bens e regalias (mesmo os que asseguram a subsistência diária).

Com facilidade se depreende que, enquanto evidência de pronunciada fratura entre os ideais que fundam a matriz identitária das democracias europeias e os referentes que formam o paradigma de orientação pelo mercado, a situação de sem-abrigo constituía um dos esqueletos que os governos se têm esforçado por manter no armário. Para além das medidas de regulação (de comportamentos e pessoas), que explicitamos de forma telegráfica nas páginas precedentes, tem vindo a disseminar-se uma política de não informação/informação parcelar no que concerne esta problemática. Veja-se, em registro ilustrativo, que apesar das constantes chamadas de atenção por parte da UE no sentido da operacionalização do construto (sem-abrigo) e de clarificação das medidas adotadas com o intuito de combater circunstâncias de privação habitacional severa, o governo português mantém uma posição pouco robusta nesta matéria (FEANTSA, 2010b; FERREIRA, 2015a).

Como veremos em seguida, vários elementos corroboram esta fragilidade. 0 primeiro deles prende-se com a inexistência de uma proposta robusta de definição, à qual se associam indicadores de operacionalização, que oriente o estudo, a intervenção e a definição de políticas neste domínio, em território nacional. Para além do Governo Português ter protelado a tarefa de assunção de uma definição explícita, dessa problemática, até 2009, quando o fez limitou-se a proceder a adaptação (via segmentação das suas categorias) da Tipologia já disseminada no seio da UE. Ressalva-se, porém, que o 
recurso à ETHOS surge sem qualquer esforço de sistematização dos elementos que sustentam a sua particular adequação e robustez, sendo esta integrada na Estratégia Nacional para a Integração de Pessoas Sem-abrigo (ENIPSA) como um dado que não requer análise crítica. Assim, é-nos dito que a situação de sem-abrigo se circunscreve a parte das categorias avançadas como integrantes da Tipologia Europeia da Situação de Sem-abrigo e Exclusão Habitacional (FEANTSA, 2007), sendo as restantes (habitação inadequada e habitação insegura) integradas na dimensão "grupo de risco", sem qualquer esforço sistemático de sustentação da sua adequação ou de suporte empírico das categorias selecionadas. Acresce ao referido que essa definição nunca foi alvo de regulamentação normativa, o que se traduz, por conseguinte, na sua (não) consideração por parte de agentes e entidades que trabalham com pessoas e famílias em circunstâncias de privação habitacional, ou seja, na manutenção de um cenário de enorme diversidade no estudo, intervenção e avaliação das ações desenvolvidas (LISBOA, 2009; COIMBRA, 2010; FERREIRA, 2015a).

Essas dificuldades na recolha e compilação de dados perpetuam, assim, uma insipiente produção de informação sistematizada e rigorosa (e.g., sobre os destinatários/as das medidas, os/as que delas usufruíram de fato, as condições em que essas ocorrem, e aqueles/as que foram impedidos mesmo que tendo manifestado intenção de as integrar, ou que poderiam integrá-las mas as rejeitaram), sendo um dos fatores responsáveis pela manutenção da crença coletiva de que, em Portugal, a situação de sem-abrigo é uma realidade com pouca expressão. A sua reduzida notoriedade deve-se, porém, a uma complexa interação de variáveis indicadoras que, com graus de intencionalidade variados, serve o efeito de (re)validar a linha de ação preconizada no país e noutros estados da UE nesta matéria. Grupos considerados de difícil acesso, no seio de uma população que é, em si mesma, descrita como hard to reach, são, pela falta de dados específicos sobre a sua existência e características específicas, sistematicamente ignorados na vasta maioria de relatórios e documentos oficiais existentes (e.g., homens/mulheres com deficiência física em situação de sem-teto, idosos/as), o que, entre outras sequelas nefastas, contribui para a perpetuação da sua invisibilidade generalizada (LISBOA, 2009; COIMBRA, 2010; FERREIRA, 2015a). 
Expõem esse enviesamento as descrições da população sem-abrigo constantes dos Planos Nacionais de Ação para a Inclusão $(\mathrm{PNAl})^{1}$ publicados desde 2000 . A sua menção nos primeiros PNAI (2001-2003, 2003-2005) é reveladora de humilde investimento na sua compreensão, sendo a caracterização apresentada limitada à apresentação de indicadores demográficos (e.g., idade, habilitações acadêmicas), à análise das problemáticas individuais (e.g., perturbação psiquiátrica, toxicodependência) e a brevíssimas referências à sua maior expressão em alguns territórios, a que se associa à indicação de um parco número de mecanismos para o seu combate (a nível preventivo e remediativo). Limitações que vemos confirmadas no próprio documento, com particular acuidade quando os seus autores se posicionam em relação à avaliação dos resultados das constritas medidas que defendem:

[...] apesar de ser positiva a informação existente sobre as Medidas enunciadas, deve reconhecer-se a insuficiência destas para o cumprimento de uma directriz preventiva de riscos de exclusão, destacando-se, neste contexto, a questão da "perda de habitação" que, tantas vezes, está na génese do aumento do número de pessoas sem-abrigo, sobretudo nas áreas urbanas, e que não foi objecto de qualquer medida (PORTUGAL, 2003, p. 20).

Assim, para além de não apresentarem análises profundas dos critérios em que sustentam essa informação positiva sobre as medidas, assumem, a priori, o seu desajuste face aos desafios específicos inerentes à situação de sem-abrigo, nos diversos territórios de Portugal continental.

O mesmo poderia dizer-se do PNAI de 2006-2008 que, embora já reconhecedor de aumento da visibilidade desta problemática, não avança qualquer estratégia coordenada de ação. Subsiste, neste documento, uma leitura superficial, que se ancora, na sua essência, numa caracterização sumária dos resultados do Estudo levado a cabo pelo Instituto de Segurança Social (2005), na qual a população é tida como globalmente desconhecida. Todavia, pese a assunção de ignorância quanto à problemática, o governo português apresenta uma sinopse do perfil da pessoa sem-abrigo, a qual é disseminada sem indicação da amostra em que se sustenta (e.g., caraterísticas, constituição, limitações na recolha e tratamento de dados) e sem qualquer referência a indicadores que ultrapassem a esfera do indivíduo (e.g., contributo do aumento de políticas de precarização do acesso e

\footnotetext{
1 Os Planos nacionais para a Inclusão encontram-se disponíveis em: <http://www.gep.msess.gov.pt/ estudos/pnai.php.>
} 
manutenção de emprego para o aumento da pobreza extrema; incrementação dos índices de exclusão social em idosos/as; inexistência de dados fidedignos sobre a percentagem de crianças, mulheres, idosos/as em situação de sem-abrigo em diversas regiões do país). Não estranha, portanto, que nesta publicação, a situação de sem-abrigo surja caraterizada segundo a seguinte referência:

Em Portugal, desconhece-se o número global de pessoas sem-abrigo. Sabe-se, contudo, que são sobretudo homens em idade activa (30 aos 49 anos), solteiros e divorciados, de nacionalidade portuguesa, com escolaridade básica, distribuídos essencialmente pelas grandes áreas metropolitanas (Lisboa e Porto), seguindo-se as cidades médias de Setúbal, Faro e Braga. Já não são somente os marginalizados clássicos, sendo visível a emergência de uma nova geração de pessoas com peso crescente de doentes mentais, toxicodependentes, alcoólicos, ex-reclusos e outras de pessoas que se encontram em situação de ruptura com as normas e instituições vigentes - quebra de laços sócio-familiares, instabilidade profissional, inacessibilidade à habitação, dificuldades de acesso ao emprego, baixos rendimentos, ausência de regras e rotinas, auto-marginalização, diluição de hábitos de trabalho, regressão nas capacidades cognitivas - e sem qualquer tipo de suporte social, psicológico e económico. Mencione-se, ainda, o aparecimento de "novos sem-abrigo", caracterizados por possuírem níveis de qualificação mais elevados (ensino secundário e curso médio/superior), que por motivos de rupturas profissionais são excluídos de participarem socialmente (PORTUGAL, 2006, p. 26-27).

De forma ainda mais curiosa, se tivermos em consideração que a sua elaboração e implementação ocorreu já no período em que a crise de 2008 se disseminava pelo hemisfério ocidental, o seu sucessor (PNAI de 2008-2010) mantém parte relevante das fragilidades que apontamos. Contemple-se, a este respeito, que embora se aponte como intenção o "abranger 80\% das pessoas identificadas como 'pessoa sem-abrigo' com Planos Individuais de Reinserção, até 2010, e disponibilizar na internet um Sistema de informação e monitorização deste problema, até final de 2009” (PORTUGAL, 2008, p. 50), estas propostas dificilmente poderão ser lidas como elementos de um alinhamento estratégico de intervenção sustentada. Mesmo na emergência de um período de incremento de constrangimentos financeiros e de dificuldades econômicas e sociais, em que se antecipava um aumento não importando o número de pessoas e famílias em circunstâncias de extrema vulnerabilidade econômica e social, o plano esboçado pelo governo português no combate à situação de sem-abrigo limita-se a uma compilação de elementos que já integravam as propostas avançadas em produção anterior. Acresce que, mesmo perante a aglomeração de indicadores de insuficiência e desajustamento das propostas centradas no 
indivíduo, não foram avançadas opções de teor social ou estrutural que viabilizassem novas linhas de conceitualização e ação nesta matéria.

Os propósitos foram muito modestos, tendo sido canalizados de forma prioritária para a sinalização de défices individuais e para a sua eventual correção a partir de propostas de apoio (aconselhamento, formação, capacitação). E, nem mesmo com a elaboração e divulgação da Estratégia Nacional para a Integração de Pessoas Sem-abrigo (ENIPSA), ocorreu um real salto evolutivo em termos de opções estratégicas. Tida como

\footnotetext{
um desenvolvimento importante no papel do estado na área da situação de semabrigo, particularmente quando se considera a relativa imaturidade do regime de protecção social português quando comparado com o contexto europeu, e a natureza fragmentada das abordagens tradicionais nos assuntos da situação de sem-abrigo (BAPTISTA, 2009, p. 54),
}

esta (aparente) mudança na abordagem foi notabilizada, em território nacional e europeu. Acreditavam os seus proponentes que a ENIPSA constituía um exemplo de boas práticas, constituindo, pela sua existência, prova de que os sistemas de proteção social mais fracos também conseguiriam propor estratégias compreensivas de combate à situação de sem-abrigo.

De fato, neste documento vimos, de forma inaugural, descrita uma proposta de "Modelo de intervenção e acompanhamento", cuja implementação se previa a nível local. Antecipava-se, ainda, e em função das necessidades identificadas em diagnóstico, a constituição de Núcleos de Planejamento e Intervenção Sem-abrigo (NPISA), a quem caberia a responsabilidade de acompanhar e implementar a estratégia, segundo os preceitos e pressupostos nelas constantes (GIMAE, 2009). Porque também ela influenciada pela matriz de governação reflexiva dominante (FERREIRA, 2015a; FUREDI, 2006a, 2006b; McNAUGHTON, 2008, 2010), a delineação das possibilidades previstas na ENIPSA centrouse na colmatação fragilidades/vulnerabilidades da pessoa (e da mobilização de recursos do sistema para este fim), em detrimento do combate a fatores estruturais e econômicos. Opção curiosa, se tivermos em linha de conta que a sua criação foi apresentada como resultado de diálogo intenso entre variadas entidades (não) governamentais [que o Instituto de Segurança Social (ISS), considerou relevantes nesta matéria] que teriam sido convidadas "a participar na identificação de problemas que estão na base destas situações e de medidas específicas com vista à sua resolução" (COMISSÃO NACIONAL PARA OS 
DIREITOS HUMANOS, 2011, p. 34). Limitações para as quais a FEANTSA não foi alheia, tendo o seu diretor alertado para a falta de clareza no processo de seleção das entidades que integraram o GIMAE e para potenciais enviesamentos resultantes desta escolha por "nomeação" (SPINNEWIJN, 2010). No mesmo sentido se posicionou quando antecipava eventuais obstáculos no desempenho do papel de liderança por parte do Instituto de Segurança Social, no período pós-criação da ENIPSA, receio que rápido se materializou. Embora proclamada como uma realidade, a sua legitimação, via inclusão nos normativos legais que regem a intervenção social no país, nunca chegou a ocorrer.

Ainda que, pela primeira vez, tenha sido proposto com um modelo estruturado de intervenção e com orientações no sentido da sua corporalização em território nacional, a sua execução ocorre(u) segundo ritmos e abordagens tão díspares nos diferentes territórios, que dificilmente se pode considerar que foram encetadas medidas ativas no sentido da regulação de procedimentos e/ou avaliação das diligências previstas/em curso. $\mathrm{Na}$ ausência de um sistema coordenado de recolha de dados, e perante limitações várias (e.g., definição dos indicadores), os resultados que vêm a público são de matriz parcelar, impossibilitando, pela sua heterogeneidade, reflexões críticas profundas sobre a problemática ou a intervenção que em Portugal se desenvolve.

Esta não importante arritmia nos padrões de execução das propostas constantes na ENIPSA, porque articulada com uma tendência, manifesta em vários territórios, de atropelamento do rigor e da profundidade na análise das ações, reforça a leitura de responsabilização do indivíduo pelas circunstâncias em que se encontra. Para além de uma considerável heterogeneidade de critérios e de níveis de profundidade analítica e reflexiva constantes nas publicações apresentadas no período pós-criação da ENIPSA (Estratégia Nacional para a Integração de Pessoas Sem Abrigo), em 2009 (LISBOA, 2009; NPISA, 2010; GPISA, 2010; COIMBRA, 2010) é sinalizável a inexistência de uma matriz coesa e articulada de intervenção nesta matéria. Considerem-se, em registro de exemplo, os seguintes excertos, retirados do Diagnóstico Social do município de Coimbra, datado de 2 de Setembro de 2013. Divulgado como o documento estruturante em que se apresentam os principais resultados da execução, no período de 2009 a 2013, um dos territórios indigitados como mais avançados nesta tarefa, neste Relatório, a intervenção é descrita da seguinte forma: 
A monitorização é feita pelos giros diários dinamizados por equipas de várias instituições e pelos gestores de caso que asseguram o acompanhamento do processo individual da pessoa sem-abrigo e a articulação com as diferentes instituições para evitar a multiplicação de respostas; [...]

A tarefa de prestar apoio a populações mais carenciadas no município de Coimbra é realizada por um conjunto de pessoas de variadas instituições que diariamente percorrem locais da cidade, distribuindo alimentação e outros bens, para além de apoio psicossocial. São pessoas que constituem equipas com larga experiência no contacto com situações desta natureza e com grande capacidade de recorrer a voluntários para reforçar a sua ação; [...]

[...] o PISACC lança anualmente um inquérito às pessoas sem-abrigo e realiza contagens desta população. Embora essas operações estatísticas careçam de melhorias metodológicas que aumentem a sua fiabilidade, a informação assim recolhida constitui um elemento de grande utilidade para caracterizar e analisar a evolução da população sem-abrigo nos últimos 3 anos; [...]

$\mathrm{Na}$ ausência de informação sistematizada mais recente, optou-se por apresentar neste relatório alguns dos principais resultados de inquéritos feitos à população sem-abrigo no ano de 2009, na medida em que as problemáticas e as questões identificadas são muito semelhantes aquelas com que os profissionais do PISACC se deparam na atualidade [...] (FERREIRA et al., 2013, p. 88, 90-92).

Não sendo intenção deste artigo proceder, de forma exaustiva, à apreciação crítica do conteúdo desta publicação, considera-se, todavia, pela evidência que em si mesma traduz, essencial alertar para a superficialidade das afirmações nela constantes, bem como para as incongruências substantivas que a corporizam. Apontada como a referência em termos de diagnóstico social do município, não se encontram citadas todas as entidades que desenvolvem a sua ação com pessoas em situação de sem-abrigo neste contexto geográfico, ocorrendo igual fenômeno no que respeita as iniciativas (planejadas e/ou executadas). Sem qualquer tentativa de quantificação ou agrupamento por tipologia, as iniciativas são apresentadas enquanto coletivo difuso [e.g., "[a] tarefa de prestar apoio a populações mais carenciadas no município de Coimbra é realizada por um conjunto de pessoas de variadas instituições que diariamente percorrem locais da cidade" (FERREIRA et al., 2013, p. 90)], impossibilitando, ao/a leitor/a, qualquer tentativa de escrutínio das iniciativas (previstas e concretizadas) e/ou de estudo comparativo entre este e outros territórios. Acrescem a essas alusões, lacunas graves a nível dos processos e instrumentos utilizados para o estudo da população em situação de sem-abrigo. Note-se, por exemplo, que na apresentação do método de análise dos dados se declara que

- PISACC lança anualmente um inquérito às pessoas sem-abrigo e realiza contagens dessa população. Embora essas operações estatísticas careçam de melhorias metodológicas que aumentem a sua fiabilidade, a informação assim 
recolhida constitui um elemento de grande utilidade para caracterizar e analisar a evolução da população sem-abrigo nos últimos 3 anos (FERREIRA et al., 2013, p. 91),

indicação que, por si só, já provoca inquietação quanto à ausência de rigor. Todavia, este cenário agrava-se ainda mais, uma vez que essa informação surge, no documento, seguida da informação que o diagnóstico de necessidades da população sem-abrigo resulta, não da compilação das informações recolhidas no final de cada ano (como mencionado na citação anterior), mas sim de um Relatório datado de 2009 [subordinado à apresentação de um estudo descritivo, em que colaborou uma amostra (não se indica de que tipo) de 496 indivíduos], assumindo, sem qualquer sustentação empírica, que as informações obtidas em 2009 são generalizáveis à realidade vivenciada em 2013. Comparam-se, em suma, informações retiradas de fontes distintas, sem se explicitar quais os cuidados tidos na análise comparativa efetuada e quais os critérios que subjazem à sinalização de determinadas variáveis como exemplificativas das caraterísticas e/ou necessidades da população em causa. De estudos distintos, realizados com recurso a amostras não probabilísticas e em tempos diversos, estabelece-se, de forma abusiva, um padrão global de características, sinalizadas como mais frequentes nos indivíduos sujeitos à intervenção das entidades que colaboraram nas pesquisas.

Em dissonância clara com as indicações explicitadas no parágrafo anterior, alega-se, neste documento, que o grupo de pessoas alvo da ação das entidades existentes no município (que, como dissemos, não foram identificadas) constitui a população que se encontra em situação de sem-abrigo. Menção que surge sem qualquer referência a eventuais limitações do diagnóstico em causa, nomeadamente (FERREIRA, 2015a, p. 6568): (i) existem, segundo o próprio documento, outras entidades no terreno, que não foram alvo de inquirição para efeitos de compilação de informação (sobre caraterísticas e necessidades das pessoas em situação de sem-abrigo ou tipologias de intervenção); (ii) assinala-se que a maior parte das Instituições (não as explicitando) concentram a sua ação noutras problemáticas (e.g., prostituição, toxicodependência) e não na situação de semabrigo; porém, não se aprecia a potencial influência enviesadora que esta atuação focalizada noutro objeto pode ter para efeitos de geração do perfil dominante dos grupos em situação de sem-abrigo (dado que as entidades apenas sinalizaram pessoas com quem contataram para efeitos de prestação de apoio); (iii) não se antecipa a possibilidade de que, 
alguns indivíduos e/ou agregados que se encontra(ra)m nessa situação, no período temporal tido em conta [todo ou em parte(s)], não tenham usufruído das iniciativas levadas a cabo pelas entidades em causa, ou que, usufruindo, tenham rejeitado colaborar na recolha de informação para este estudo.

Urge, pelo exposto, que o compromisso assumido, pelas entidades locais e pelos responsáveis pela criação e gestão da ENIPSA (GIMAE, 2009), traduza-se em intervenções, de qualidade, estruturadas segundo premissas de ação dignificadora e sustentada em princípios éticos claros. Imprescindível é, também, e implementação de estratégias de monitorização/avaliação, que ancorem em níveis aceitáveis de rigor, exigíveis a qualquer esforço de diagnóstico social ou outros trabalhos de caraterização de populações em circunstâncias de vulnerabilidade e/ou das iniciativas existentes. Pretende-se, neste enquadramento, que a sua produção concorra para robusta sistematização dos mecanismos e ferramentas (já) existentes e, em articulação, para a (re)definição de prioridades e afetação de recursos, e não para a perpetuação e leituras circunscritas e enviesadas sobre a situação de sem-abrigo e as pessoas que a experienciam. Como aludiu Spinnewijn (2010, p. 2), se no seio da própria estratégia nacional portuguesa não se gerarem as condições estruturantes para que a monitorização ocorra com qualidade a recolha de dados e avaliação transformar-se-ão em meros exercícios de papel. Em resultado, e perante negligência severa na recolha e compilação de informações (segundo uma matriz objetivada, fundamentada, e implementada, em efetivo, nos diferentes territórios), os resultados que vêm a público não materializam qualquer contributo de relevo, seja no âmbito do conhecimento da problemática, seja no das políticas e práticas existentes/previstas.

\section{Conclusão}

Evidência de desigualdades severas, a situação de sem-abrigo constitui, na memória coletiva, a incômoda lembrança de que, em contraste com os princípios assumidos na legislação nacional ou expostos como referentes estruturantes da União Europeia [cf., Carta dos direitos fundamentais da União Europeia (2010/C 83/02)], as circunstâncias de muitas pessoas e famílias desafiam os mais basilares padrões de dignidade da vida humana. Ilustração objetiva de que o arquétipo constante nas orientações e normativos 
(inter)nacionais sobre igualdade, liberdade e solidariedade entre pessoas e povos não se materializa para todos/as, a experiência da situação de sem-abrigo expõe, de forma crua, as pronunciadas limitações inerentes ao macro modelo de governação privilegiado nas democracias ocidentais. A intensificação da sua expressão, na vasta maioria dos territórios europeus (incluindo o português), com acentuada dilatação no período pós-crise de 2008 , corporiza os efeitos nefastos da atual conjuntura global de instabilidade, evidenciando desequilíbrios vários, não apenas no que respeita aos mecanismos de regulação implementados pela UE, mas, igualmente, em relação ao desajuste e desorientação evidenciados nas parcas propostas avançadas no nosso país.

Portugal não escapa a esta tendência de dominação pela matriz de orientação pelo e para o mercado, revelando intensas fragilidades no alinhamento estratégico que defende. Em resultado, verificou-se uma incipiente evolução no âmbito da ação coordenada neste domínio, a que se associa reduzido investimento na compreensão do fenômeno, assim como na sustentação das medidas de intervenção propostas nos últimos anos. Relembramos que não existe regulamentação normativa em que se operacionaliza o construto "situação de sem-abrigo", em Portugal, sendo coexistentes diversas leituras e, em paralelo, opções de intervenção substantivamente distintas. Acresce ao referido que não existem, até a data, dados estatísticos nacionais fiáveis sobre esta população, seja por meio da informação disponibilizada pelo Instituto Nacional de Estatística (e respeitante ao Censos de 2011), seja em resultado da sistematização elaborada por entidades governamentais que desenvolvem a sua ação com pessoas em circunstância de privação severa, tais como as autarquias ou o próprio Instituto de segurança Social (FERREIRA, 2015a). Se, por exemplo, Ferreira (2015a) aponta para um universo que ascende a mais de 700 pessoas adultas, resultante da compilação de dados efetuada pelo PISACC só para o município de Coimbra, os Censos de 2011 reporta 696 pessoas em situação de sem-abrigo em todo o território nacional, indicando que 66 se encontram na região centro do país (território bem mais vasto do que o município de Coimbra e do qual este último faz parte).

Mantém-se, portanto, uma navegação à vista, resultante da ausência de cartografia rigorosa, na qual são múltiplos os naufrágios, pesem os alertas emanados por vários organismos internacionais, de que é urgente maior seriedade no estudo, na definição de políticas e orientações estratégicas, assim como nas opções concretas de intervenção 
preconizadas e efetivadas. Faz-se necessário, por conseguinte, um investimento coerente no estudo, intervenção, e regulamentação de políticas públicas de combate a esta manifestação severa de privação e de exclusão social, as quais possibilitem avanços substantivos na promoção da qualidade e bem-estar de pessoas e agregados. Propomos, neste arigo, o afastamento de abordagens reflexivas, típicas de alinhamentos governativos centrados no mercado, em detrimento da geração de políticas públicas cientificamente fundamentadas e centradas no propósito global da promoção da justiça social e da equidade.

\section{Referências}

BAPTISTA, I. The drafting of the Portuguese homeless strategy: an insight into the process from a governance-oriented perspective. European Journal of Homelessness, Belgium, v. 3, p. 53-74, 2009.

BROUSSE, C. The production of data on homelessness and housing deprivation in the European Union: survey and proposals. Luxembourg: Office for Official Publications of the European Communities, 2004.

BUSCH-GEERTSEMA, V. et al. Homelessness \& homeless policies in Europe: Lessons from research. 2010. Disponível em: <http://www.york.ac.uk/inst/chp/publications/PDF/ EUHomelessPoliciesEurope.pdf>. Acesso em: 20 fev. 2012.

CALLAN, T. et al. The distributional effects of austerity measures: a comparison of six EU countries. 2011. Disponível em:

<https://www.iser.essex.ac.uk/research/publications/working-papers/euromod/em611.pdf>. Acesso em: 3 mar. 2012. EUROPEAN COMMISSION

CHOMSKY, N. Profit over people: neoliberalism and global order. New York: Seven Stories Press, 1999.

COHEN, S.; DELONG, B. The end of influence: what happens when other countries have the money. New York: Basic Books, 2010.

COIMBRA. Camara Municipal. Rede Social. Plano de ação 2010. Coimbra, 2010. Disponível em: <http://www.cm-coimbra.pt/index.php?option=com_docman\&task=doc_ download\&gid=3394\&ltemid=381>. Acesso em: 3 dez. 2012.

COMISSÃO NACIONAL PARA OS DIREITOS HUMANOS. Relatório de actividades. Lisboa, 2011. Disponível em: <http://www.portugal.gov.pt/media/417830/

r04_relatorio_de_atividades.pdf>. Acesso em: 6 fev. 2013.

EUROPEAN CENTRAL BANK. Joint press statement by the European Commission and the European Central Bank on the Measures announced by the Portuguese government. 2011. 
Disponível em: <http://www.ecb.int/press/pr/date/2011/html/pr110311.en.html>. Acesso em: 3 mar. 2012.

EUROPEAN COMMISSION. Constructing understandings of homeless populations. 2007. Disponível em: <http://cordis.europa.eu/documents/documentlibrary/ 100124281EN6.pdf>. Acesso em: 12 jun. 2009.

EUROPEAN PARLIAMENT. Citizens' agora on crises and poverty: civil society to table proposals. 2011. Disponível em: <http://www.europarl.europa.eu/news/en/pressroom/ content/20110124IPR12355/html/>. Acesso em: 11 mar. 2013.

FEANTSA - FEDERATION EUROPEENNE DES ASSOCIATIONS NATIONALES TRAVAILLANT AVEC LES SANS-ABRI. ETHOS - European typology on homelessness and housing exclusion. 2007. Disponível em: <http://www.feantsa.org/code/en/pg.asp?page=484>. Acesso em: 5 abr. 2011.

European urban knowledge network. 2010a. Disponível em:

<http://www.eukn.org/E_library/Housing/Housing_Policy/Homelessness/From_managin g_to_ending_homelessness_in_Europe_a_guide_for_policy_makers $>$. Acesso em: 5 abr. 2011.

European consensus conference on homelessness: policy recommendations of the jury. 2010b. Disponível em: <http://www.feantsa.org/files/freshstart

/Consensus_Conference/Outcomes/2011_02_16_FINAL_Consensus_Conference_Jury_ Recommendations_EN.pdf>. Acesso em: 21 abr. 2011.

FERREIRA, J. et al. Diagnóstico social do município de Coimbra - 2013. Coimbra: Rede Social de Coimbra, 2013.

FERREIRA, S. M. À luz da lua, na face negra da terra. Tese (Doutoramento em Ciências da Educação) - Faculdade de Psicologia e de Ciências da Educação da Universidade de Coimbra, Coimbra, 2015a.

. Gendered survival strategies of Portuguese homeless adults: Communalities and singularities of women and men experiences. In: INTERNATIONAL MULTIDISCIPLINARY SCIENTIFIC CONFERENCES. Psychology and psychiatry, sociology and health care, education, book series: International multidisciplinary scientific conferences on social sciences and arts. Bulgaria, 2015b. p. 77-84.

Surviving the streets: an original grounded theory of homeless trajectories in Portugal. In: INTERNATIONAL MULTIDISCIPLINARY SCIENTIFIC CONFERENCES. Psychology and psychiatry, sociology and health care, education, book series: International multidisciplinary scientific conferences on social sciences and arts. Bulgaria, 2015c. p. 211-218.

. Training, transitions and employment in homeless Portuguese population. In: INTERNATIONAL MULTIDISCIPLINARY SCIENTIFIC CONFERENCES. Psychology and psychiatry, sociology and health care, education, book series: International multidisciplinary scientific conferences on social sciences and arts. Bulgaria, 2015d. p. 243-250. 
FUREDI, F. Save us from the politics of behaviour. 2006a. Disponível em: <http://www.spiked-online.com/newsite/article/1638\#.UhI8iZK1GDg>. Acesso em: 12 nov. 2010.

Taking the social out of policy: a critique of the politics of behavior. In: FUREDI, F. (Ed.). Diverse Britain: social practice and social policy conference. London: Keyworth Center, 2006b.

GIMAE - GRUPO DE IMPLEMENTAÇÃO, MONITORIZAÇÃO E AVALIAÇÃO DA ESTRATÉGIA. Estratégia nacional para a integração de pessoas sem-abrigo. 2009. Disponível em: <http://www.seg-social.pt/documents/10152/13334/ enipsa_2009_2015>. Acesso em: 16 set. 2012.

GPISA - GRUPO DE PLANEAMENTO DA INTERVENÇÃO COM OS SEM-ABRIGO. Plano concelhio para a integração de pessoas sem-abrigo 2010-2013. Cascais, maio 2010. Disponível em: <http://www.cm-cascais.pt/sites/default/files/anexos/gerais/ planoconcelhioparaaintegraodepessoassemabrigo1.pdf>. Acesso em: 10 fev 2012.

INSTITUTO DA SEGURANÇA SOCIAL. Estudo dos sem-abrigo. 2005. Disponível em: <http://195.245.197.196/left.asp?05.18.08.03>. Acesso em: 3 mar. 2007.

INSTITUTO FINANCEIRO PARA O DESENVOLVIMENTO REGIONAL. Aprovado programa nacional de reformas Portugal 2020. 2011. Disponível em:

<http://www.ifdr.pt/content.aspx?menuid=22\&eid=4763>. Acesso em: 3 mar. 2012.

INSTITUTO NACIONAL DE ESTATÍSTICA. Indicadores sociais 2010. 2011. Disponível em: $<$ http://www.ine.pt>. Acesso em: 3 mar. 2012.

LEE, B.; GREIF, M. Homelessness and hunger. Journal of Health and Social Behavior, Albany, v. 49, n. 1, p. 3-19, 2008.

LISBOA. Rede Social. Grupo de Trabalho da Pessoa sem Abrigo. Plano cidade para a pessoa. Lisboa, 2009. Disponível em: < http://habitacao.cm-

lisboa.pt/documentos/1333441745G2qZO3ok3Cy66Q06.pdf>. Acesso em: 17 abr. 2011

McNAUGHTON, C. Transitions through homelessness: lives on the edge. New York: Palgrave Macmillan, 2008.

. Housing, homelessness, and capabilities. Housing Theory and Society, Philadelphia, v. 27, n. 1, p. 23-41, 2010.

MILIOS, J. Neoliberal Europe in crisis: SYRIZA's alternative. 2013. Disponível em: <crisis: http://users.ntua.gr/jmilios/SF_Milios.pdf> Acesso em: 20 ago. 2013.

NPISA - NÚCLEO DE PLANEAMENTO E IMPLEMENTAÇÃO SEM-ABRIGO DO CONCELHO DE SETÚBAL. Núcleo de planeamento e intervenção sem-abrigo de Setúbal. 2010. Disponível em: <http://redesocial.mun-setubal.pt/page6/downloads-2/files/NPISA_protocolo.pdf>. Acesso em: 12 mar. 2011.

PAASCHE, S. Is anti-begging legislation 'good practice' in tackling homeless? 2012. Disponível em: <http://www.povertyisnotacrime.org>. Acesso em: 5 jan 2013. 
PALLEY, T. Europe's crisis without end: the consequences of neoliberalism run amok. 2013. Disponível em: <http://www.boeckler.de/pdf/p_imk_wp_111_2013>. Acesso em: 15 ago. 2013.

PARSELL, C.; PARSELL, M. "Homelessness as a choice", Housing, Theory and Society, v. 29, n. 4, p. 420-434, 2012.

PORTUGAL. Ministério do Trabalho e da Solidariedade Social. Plano Nacional de Acção para a Inclusão 2003-2005 (PNAI), Lisboa, 2003. Disponível em:

<http://www.gep.msess.gov.pt/estudos/peis/pnai0305_pt.pdf>. Acesso em: 15 mar. 2015.

Ministério do Trabalho e da Solidariedade Social. Plano Nacional de Aç̧ão para a Inclusão 2006-2008 (PNAI), Lisboa, out. 2006. Disponível em:

<http://www.gep.msess.gov.pt/estudos/peis/pnai0608_pt.pdf>. Acesso em: 15 mar. 2015.

Ministério do Trabalho e da Solidariedade Social. Plano Nacional de Acção para a Inclusão 2008-2010 (PNAI), Lisboa, mar. 2008.

SPINNEWIJN, F. How to use the open method of coordination to deliver policy progress at european level: the example of homelessness. European Journal of Homelessness, Belgium, v. 3, p. 301-316, 2009.

Some reflections on the Portuguese homelessness strategy. 2010. Disponível em: <http://feantsa.horus.be/files/freshstart/Communications/Flash\%20EN/PDF_2010/10_11 _November_FEANTSA_Flash_EN.pdf>. Acesso em: 5 set. 2012.

WORLD HEALTH ORGANIZATION. Regional Office for Europe. Poverty, social exclusion and health systems in the WHO European Region. Copenhagen: WHO Regional Office for Europe, 2010. Disponível em: <http://www.euro.who.int/_data/assets/pdf_file/ 0004/127525/ e94499.pdf>. Acesso em: 13 abr. 2011.

ZACUNE, J. Privatising Europe. Using the crisis to entrench neoliberalismo. 2013. Disponível em: <http://www.tni.org/sites/www.tni.org/files/download/ privatising_europe.pdf $>$. Acesso em: 19 dez. 2013. 